\title{
NETMET: A Program For Generating \& Interpreting Metaphors
}

Eric Steinhart. Published as (1995) NETMET: A program for generating and interpreting metaphors. Computers and Humanities 28 (6), 383-392.

ABSTRACT: Metaphors have computable semantics. A program called NETMET both generates metaphors and produces partial literal interpretations of metaphors. NETMET is based on Kittay's semantic field theory of metaphor and Black's interaction theory of metaphor. Input to NETMET consists of a list of literal propositions. NETMET creates metaphors by finding topic and source semantic fields, producing an analogical map from source to topic, then generating utterances in which terms in the source are identified with or predicated of terms in the topic. Given a metaphor, NETMET utilizes if-then rules to generate the implication complex of that metaphor. The literal leaves of the implication complex comprise a partial literal interpretation.

\section{Introduction}

The humanities routinely utilize metaphors. Literature and rhetoric depend heavily upon metaphors, and literary theory also makes use of metaphors. Though it often condemns metaphor, philosophy often makes essential use of it. Outside of the humanities proper, theology and science also make use of metaphors. Literary, linguistic, comparative, and philosophical studies of discourses in all disciplines of the humanities, and also of disciplines outside the humanities, require clear theories of metaphor in order to proceed.

Although the production and interpretation of metaphors have often been thought of as the paradigms of linguistic creativity, the production and interpretation of metaphor are not acts of creation ex nihil. The production and interpretation of metaphors are rule-governed activities, just as all linguistic activity is rule-governed. We do not believe that this rule-governedness conflicts with the creative nature of metaphor production and interpretation. Indeed, we believe that a study of the rules involved in producing and generating metaphors precisely illuminates the creativity required to produce and interpret them.

To say that the production and interpretation of metaphors is rule-governed is to say that metaphors have rule-governed semantics. If metaphors have rule-governed semantics, their production and interpretation should be computable. Yet metaphors have so far strongly resisted computational modeling. As computational techniques for dealing with similarities and analogies become refined, the resistance of metaphor to computability is falling. Indeed, a program named NETMET now exists that is able to generate syntactically and semantically complex metaphors. ${ }^{1}$ NETMET is also able to provide at least partial literal interpretations for metaphorical predications.

While the ability of a program to produce and interpret metaphors has consequences for all the disciplines in the humanities, it has particularly potent consequences for philosophy, especially the philosophy of language. The ability of a computer program to generate metaphors challenges many classical assumptions in the philosophy of language. For instance, it challenges the Davidsonian claim that "There are no instructions for devising metaphors" (Davidson, 1978). Twentieth century philosophy of language, 
preoccupied with the semantics of logic, mathematics, and science, eschews understanding of poetical discourse and rhetoric. It is hoped that a computational model of metaphor will encourage twenty-first century philosophy to pay closer attention to poetical discourse and rhetoric, and therefore to bring philosophy of language into closer contact with literature.

NETMET is an example of work in the computational philosophy of language. As such it is an instance of work in computational philosophy in general. Computational philosophy aims to produce computational models of philosophical theories. NETMET is a computational model of Kittay's (1987) semantic field theory of metaphor (henceforth referred to as "SFTM"). More generally, NETMET is a model of Black's interactionist theory of metaphor (Black, 1962, 1979). We refer to the process of creating a computational model from a philosophical theory as implementing the theory. Implementation requires translation of a philosophical text (usually written mostly in a natural language like English) into a computer program written in a computer language (such as PROLOG, LISP, or C). If a philosophical theory contains inconsistencies or incompletenesses, it is not implementable, and has no computational model. Conversely, if a philosophical theory is implementable, that is, if it has a computational model, then that theory is consistent and internally complete. Successful implementation of a philosophical theory provides computational confirmation of that theory. NETMET provides computational confirmation for Kittay's semantic field theory of metaphor and Black's interactionist theory.

Although NETMET has been preceded by other computational approaches to metaphor (Carbonell \& Minton, 1985; Indurkhya, 1987), it is the only theory of metaphor we know of that has actually been implemented in a working computer program. NETMET is a hybrid computational model, utilizing both the serial symbol processing techniques of classical artificial intelligence and more recent connectionist techniques (Rumelhart et al., 1986).

\section{Input to NETMET}

NETMET takes a finite set of propositions as its input. Each proposition given to NETMET expresses a simple fact. It is assumed that these propositions are literal, true in the actual world or in some possible world, and non-paradoxical. Importantly, NETMET does not assume that its input contains literal language capable of supporting analogies or metaphors; if NETMET cannot generate any analogies or metaphors based on its input, it informs the user of this fact.

For ease of computer interpretation, the propositions given to NETMET are written in a simplified grammatical notation similar to the predicate calculus. NETMET stores its set of input propositions internally as a semantic network. Semantic networks have a long history in psychology (Collins \& Loftus, 1975; Norman \& Rumelhart, 1975). Although the details of NETMET's semantic networks are not important here, semantic networks can be viewed as networks of words linked together by their lexical relations. For instance, the antonyms "up" and "down" would be connected by a link labelled with the relation ANTONYM to express their lexical opposition. 
NETMET uses lexical semantics (Lyons, 1977; Cruse, 1986) to determine the kind of information its input propositions encode. There are 7 basic kinds of propositions given to NETMET: (1) sentential propositions; (2) attribute-value propositions; (3) features; (4) rules; (5) genitive propositions; (6) paradigmatic propositions; (7) mereological propositions. Each of these is discussed below.

(1) A sentential proposition basically encodes a sentence consisting of a verb and some nouns. The relations between the verb and each noun in the sentence are explicitly indicated. It has the form $\mathrm{V}\left(\mathrm{T}_{1}: \mathrm{N}_{1}, \mathrm{~T}_{2}: \mathrm{N}_{2}, \ldots \mathrm{T}_{\mathrm{n}}: \mathrm{N}_{\mathrm{n}}\right)$, where $\mathrm{V}$ is a verb, $\mathrm{N}_{\mathrm{i}}$ are nouns, and $\mathrm{T}_{\mathrm{i}}$ are thematic roles, such as AGENT, PATIENT, and INSTRUMENT. For example, "A mother gives birth to a baby" is encoded as "gives-birth( AGENT: mother, PATIENT: baby)" is a sentential proposition.

(2) An attribute-value proposition has expresses the fact that some kind of thing has a property which takes on several values. For instancce, "color" is a property of a "thing", and this property takes on the values "red", "yellow", etc. Such a proposition has the form PROPERTY(P-of $(\mathrm{O})$, is: $\left\{\mathrm{V}_{1}, \mathrm{~V}_{2}, \ldots \mathrm{V}_{\mathrm{n}}\right\}$ ) where $\mathrm{P}$ is an attribute, $\mathrm{O}$ is a noun, and $\mathrm{V}_{\mathrm{i}}$ are adjectives. For instance, "The gender of a human is either male or female" is written as "PROPERTY(gender-of(human), is:\{male, female\})" is an attribute-value proposition.

(3) A feature proposition indicates that a noun has a feature. For instance "blue" is a feature of "sky". Features, it should be noted, are related to attributes. A feature proposition has the form FEATURE $(\mathrm{P}-\mathrm{of}(\mathrm{O})$, is: $\mathrm{V})$ where $\mathrm{P}$ is an attribute, $\mathrm{O}$ is a noun, and $\mathrm{V}$ is some value of the attribute $\mathrm{P}$. For instance, "The gender of Socrates is male" is written as "FEATURE(gender-of(Socrates), is:male)".

(4) Rules provide logical links between sentential propositions. A rule expresses that a fact has consequences. For instance if it rains, then the ground gets wet expresses a relation between "it rains" and "the ground gets wet". Rules have the form "if $\mathrm{P}$ then \{ $\left.\mathrm{Q}_{1}, \mathrm{Q}_{2}, \ldots \mathrm{Q}_{\mathrm{n}}\right\}^{\prime \prime}$ where $\mathrm{P}$ and $\mathrm{Q}_{\mathrm{i}}$ are sentential propositions. The $\mathrm{Q}_{\mathrm{i}}$ are interpreted as forming a conjunction. The proposition $\mathrm{P}$ is called the antecedent of the rule; the Qi are called its consequents.

(5) Genitive propositions indicate the usage of the preposition "of". Such usage is important for metaphors of the form " $\mathrm{X}$ is the $\mathrm{Y}$ of $\mathrm{Z}$ ". A genitive proposition has the form $\operatorname{OF}\left(N_{1}, N_{2}\right)$ and indicates that $N_{1}$ is the $N_{1}$ of $N_{2}$. For example, speaking of midwifery we might want to record that the midwife is the midwife of the mother. We do this by writing $\mathrm{OF}$ (midwife, mother).

(6) Paradigmatic propositions indicate contrasts between terms. such as "black"/"white", "up"/"down", "man"/"woman", "enter"/"exit". A paradigmatic proposition has the form $\mathrm{R}\left(\mathrm{P}_{1}: \mathrm{A}_{1}, \ldots \mathrm{P}_{\mathrm{n}}: \mathrm{A}_{\mathrm{n}}\right)$, where $\mathrm{R}$ is a contrastive relation, $\mathrm{A}_{i}$ are words in the same grammatical category, and the $\mathrm{P}_{\mathrm{i}}$ are paradigmatic roles. For example, OPPOSITE( POSITIVE: light, NEGATIVE: dark) indicates that "light" and "dark" are opposites, and that "light" is the positive term.

(7) Mereological propositions indicate part-whole relations. A mereological proposition has the form CONTAINS(WHOLE: $\mathrm{N}_{1}$, PART: $\mathrm{N}_{2}$ ) where CONTAINS is a general mereological relation, and $\mathrm{N}_{1}$ is a noun that contains $\mathrm{N}_{2}$. For example, CONTAINS( WHOLE: person, PART: brain) is a mereological proposition. 


\section{The Semantic Field Theory of Metaphor}

According to SFTM (Kittay, 1987) metaphors arise from the interaction of two analogous but distinct semantic fields. Semantic fields are clusters of associated propositions (hence clusters of associated terms). The two fields involved in a metaphor are traditionally called the target and the source. For instance, the metaphor "Socrates is a midwife" arises from the interaction of the semantic field of intellectual (and artistic) creativity with that of human reproduction. It is based on the analogy "Socrates is to the students he cares for as a midwife is to the mothers she cares for". The shared relation of caring makes Socrates analogous to a midwife.

In claiming that metaphors are based on analogous semantic fields, SFTM is an analogy theory of metaphor. As such, it has numerous precedents. Aristotle (1984, p. 57b1-30) claims that metaphors are derived from analogies. Kintsch (1972, p. 280) asserts that metaphors are produced and understood using "analogy rules." Miller (1979, p. 231) argues that proportional metaphors of the form " $\mathrm{X}$ is the $\mathrm{Y}$ of $\mathrm{Z}$ " are based on analogical comparisons. Carbonell \& Minton (1985, p. 407) assert that analogical reasoning is the "underlying cognitive process" of which metapors are linguistic manifestations. Indurkhya (1987, p. 446) assumes that "there is a structural analogy underlying every metaphor." Kittay (1987, p. 169) posits a metaphorical function that satisfies the traditional definition of an analogy. Gentner, Falkenhainer, and Skorstad (1988) claim that relational metaphors can be analyzed as analogies.

\section{Semantic Fields}

Semantic fields consist of clusters of propositions whose terms are densely interconnected by associations in semantic memory. They can be thought of in terms of the scripts proposed by Schank and Abelson (1977), the experiential gestalts proposed by Lakoff and Johnson (1980), the schemas of Goodman (1976), or the semantic fields proposed by Kittay (1987). Nouns play an important role in determining the contents of fields. Nouns belonging to the same field typically have "a lot to do with one another", that is, they are involved in many sentential propositions together. Nouns belonging to distinct fields typically have little to do with one another; they are involved in few sentential propositions together. For instance, terms like "mother", "baby", and "midwife" have a lot to do with one another, because a mother, her baby, and her midwife interact with one another in many complex ways. However, terms like "photon", "trinity" and "toothbrush" do not have much to do with one another.

NETMET contains algorithms for clustering terms into semantic fields. Cluster analysis, however, is an extremely difficult process, and the clustering algorithms of NETMET are not very sophisticated. Although the clustering algorithms in NETMET yield acceptable results for simple systems of terms, they do not function very successfully on more complex cases. Future work on NETMET will aim at improving its clustering algorithms. In the mean time, NETMET enables the user to explicitly group propositions into semantic fields by specifying such groupings in the input file. A semantic field has the form FIELD $\left\{\mathrm{P}_{1}, \mathrm{P}_{2}, \ldots \mathrm{P}_{\mathrm{n}}\right\}$ where $\mathrm{P}_{\mathrm{i}}$ is a proposition. The propositions enclosed in curly braces are all put into the same semantic field. Table 1 
shows two semantic fields taken from Plato's (1984) SOCRATES IS A MIDWIFE analogy.

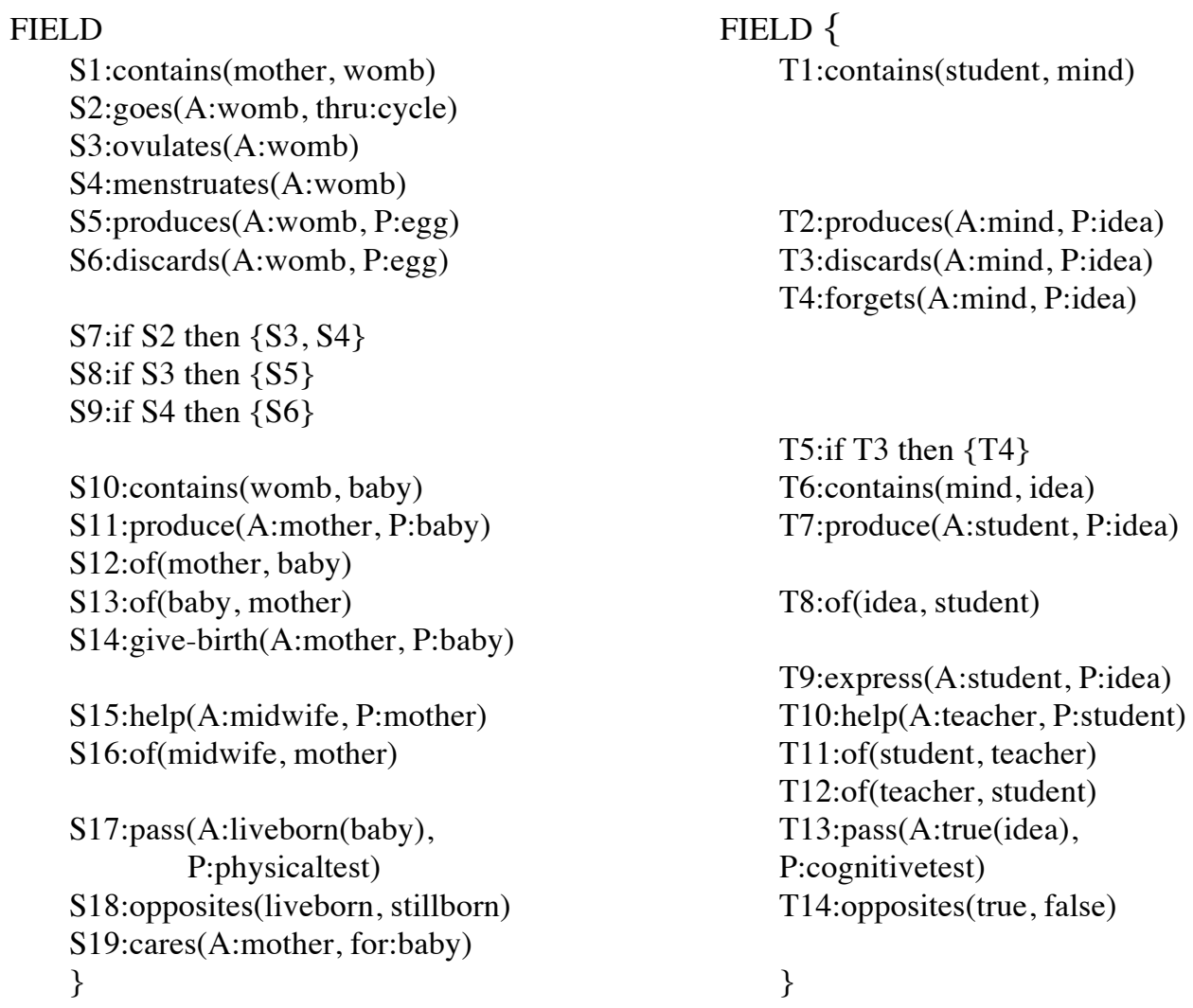

Table 1. Fields from Plato's SOCRATES IS A MIDWIFE analogy.

\section{Analogies Underlying Metaphors}

Since it claims that metaphors are generated from analogies, SFTM requires a theory of analogy. Examples of analogies are statements of the form "A is to B as C is to D". Recently, highly formalized theories of the semantics of analogies have been developed by Gentner (1982, 1983), Falkenhainer, Forbus \& Gentner (1989), and Holyoak \& Thagard $(1989,1990)$.

According to these theories, an analogy is a triple $\left(S, T, f_{M}\right)$ where $S$ and $T$ are systems of terms or concepts and the analogical mapping function $\mathrm{f}_{\mathrm{M}}$ is a function pairing terms in $\mathrm{S}$ with their analogoues in $\mathrm{T}$. For us, $\mathrm{S}$ and $\mathrm{T}$ are semantic fields. For instance, in the SOCRATES IS A MIDWIFE analogy, we would let $\mathrm{T}$ be the field of intellectual creativity and $S$ be the field of human reproduction. The analogical mapping function $f_{M}$ is a set of ordered pairs $(s, t)$ where $s$ is in the source field $S$ and $t$ is in the target field $T$. For example, if "A is to B as C is to D", then $(A, C)$ and $(B, D)$ are ordered pairs in the analogical mapping function. For instance, "Socrates is to the students he cares for as a midwife is to the mothers she cares for" yields the pairs (Socrates, midwife) and (students, mothers). These pairs form an analogical mapping function that pairs 
"Socrates" with its analogue "midwife" and "students" with its analogue "mothers". Importantly, the analogical mapping function must preserve the relational structure of the source. Formally, the analogical mapping function $\mathrm{f}_{\mathrm{M}}$ preserves the relational structure of the source to the extent that the existence of a relation $\mathrm{R}$ between source terms $\mathrm{x}$ and $\mathrm{y}$ implies the existence of a relation $R$ between target terms $f_{M}(x)$ and $f_{M}(y)$. For instance, the analogical mapping function $\{$ (Socrates, midwife), (students, mothers) $\}$ preserves the relation "cares".

The generation of an analogy is traditionally divided into two major subphases: (1) the access phase, (2) the mapping phase (Hall, 1989). NETMET follows this traditional division. The access phase generates the target and source fields of an analogy. To generate these fields, NETMET begins with a cue. The cue is a single word (or concept) such as "idea". ${ }^{2}$ NETMET then generates the semantic fields in which the cue is a member. NETMET generates these semantic fields by finding the propositions in which the cue participates, and then by partitioning the terms in those propositions into densely-interconnected subsets. For instance, if the cue "idea" is used with the semantic fields from Table 1, NETMET would find that "mind", "student", and "teacher" are all closely related terms. Once the semantic fields of the cue have been generated, one must be selected as the target. ${ }^{3}$ Once the target field is selected, NETMET generates fields that are analogous to the target. These are the candidate source fields. In order to be analogous, two fields must share predicative terms. NETMET finds candidate source fields by spreading activation from predicative terms in the target to other terms outside of the target. Once the candidate source fields have been generated, one must be selected as the source. ${ }^{4}$

After analogical access has produced a target and source field, the analogical mapping phase generates the analogical mapping function $f_{M}$ that maps the source onto the target. Recall that the analogical mapping function is a set of ordered pairs $(\mathrm{s}, \mathrm{t})$ where $s$ is in the source and $t$ in the target. The ordered pairs in $f_{M}$ must preserve as much of the relational structure of the source as possible. Several mapping principles are used to generate ordered pairs that preserve the relational structure of the source field. Basically, one principle is used for each different type of proposition. Here, however, we outline only three mapping principles.

The first principle is traditionally known as the principle of proportional analogy. It is a generalized version of "A is to B as C is to D". To see the motivation behind the principle, consider that the source proposition "cares( AGENT:midwife, FOR:mothers)" and the target proposition "cares( AGENT:Socrates, FOR:students)" yields the mapping of "Socrates" onto "midwife" and "mothers" onto "students". We can generalize this to sentences with any number of nouns. Formally, if $F=V\left(T_{1}: X_{1}, T_{2}: X_{2}, \ldots T_{n}: X_{n}\right)$ is a sentential proposition in the source and $\mathrm{V}\left(\mathrm{T}_{1}: \mathrm{Y}_{1}, \mathrm{~T}_{2}: \mathrm{Y}_{2}, \ldots \mathrm{T}_{\mathrm{n}}: \mathrm{Y}_{\mathrm{n}}\right)$ is a sentential proposition in the target, then $f_{M}$ preserves the local relational structure of source proposition $\mathrm{F}$ by mapping $\mathrm{X}_{\mathrm{i}}$ onto $\mathrm{Y}_{\mathrm{i}}$ for $\mathrm{i}=1$ to $\mathrm{n}$.

The second principle is the principle of mereological analogy. This principle is motivated by the consideration that analogous parts should be in analogous wholes. For instance, if a watch-spring is analogous to a heart, then the watch should be analogous to the whole animal. Formally, if $\mathrm{F}=\operatorname{CONTAINS}\left(\mathrm{W}_{\mathrm{S}}, \mathrm{P}_{\mathrm{S}}\right)$ is a mereological proposition in the source field and CONTAINS $\left(\mathrm{W}_{\mathrm{T}}, \mathrm{P}_{\mathrm{T}}\right)$ is a mereological proposition in the target, and if 
$f_{M}\left(P_{S}\right)$ is $P_{T}$, then $f_{M}$ preserves the local relational structure of $F$ by mapping $W_{S}$ onto $\mathrm{W}_{\mathrm{T}}$.

The third principle is the principle of extension to paradigmatic contrast sets. It is inspired by the consideration that pairs of opposites should be analogous. For instance, if "brother" is analogous to "white", then "sister" should be analogous to "black" to preserve the structure of the two oppositions. Formally, if $f_{M}$ maps a noun $\mathrm{N}_{S}$ in the source onto a noun $\mathrm{N}_{\mathrm{T}}$ in the target, and if $\mathrm{A}_{\mathrm{Si}}$ modifies $\mathrm{N}_{\mathrm{S}}$ and $\mathrm{A}_{\mathrm{Ti}}$ modifies $\mathrm{N}_{\mathrm{T}}$, and if $\mathrm{F}=\mathrm{R}\left(\mathrm{P}_{1}: \mathrm{A}_{\mathrm{S} 1}\right.$, . . $\left.\mathrm{P}_{\mathrm{n}}: \mathrm{A}_{\mathrm{Sn}}\right)$ is a paradigmatic proposition in the source and $\mathrm{R}\left(\mathrm{P}_{1}: \mathrm{A}_{\mathrm{T} 1}, \ldots \mathrm{P}_{\mathrm{n}}: \mathrm{A}_{\mathrm{Tn}}\right)$ is a paradigmatic proposition in the target, then $\mathrm{f}_{\mathrm{M}}$ preserves the local relational structure of the source frame $\mathrm{F}$ by mapping $\mathrm{A}_{\mathrm{Si}}$ onto $\mathrm{A}_{\mathrm{Ti}}$.

The three principles outlined above all generate ordered pairs preserving local relational structure of the source. Unfortunately, local relational structure relational structure often yields conflicting analogies. To see this, consider that an analogy in which the source field is the solar system and the target is the atom might have the propositions "orbits( planet, sun)", "orbits( moon, planet)", and "orbits( electron, nucleus)". Proportional analogies would yield the pairs (electron, moon), (electron, planet), (nucleus, planet), (nucleus, sun). Such a situation is confusing.

In order to overcome conflicts generated by local applications of the principles, the ordered pairs generated by local applications to different propositions in the source field must be combined into a global mapping function that preserves as much of the overall relational structure of the source field as possible. Creation of the global mapping function requires resolution of local conflicts. In contemporary analogy theories, the global mapping function emerges through the logical interaction of the local ordered pairs. Two ordered pairs induced by local application of the principles are either consistent or inconsistent. In general, if two ordered pairs $(\mathrm{a}, \mathrm{b})$ and $(\mathrm{x}, \mathrm{y})$ are generated by one application of one rule, then they are consistent. If two ordered pairs contain the same first element, but not the same second element, or contain the same second element, but not the same first element, they are inconsistent. Consistency is a positive local constraint on the global map; inconsistency is a negative local constraint on the global map. Following Holyoak \& Thagard $(1989,1990)$, SFTM holds that the best global map is the one that best satisfies all the positive and negative local constraints.

The mapping phase finds the analogical mapping function $\mathrm{f}_{\mathrm{M}}$ by treating the system of interrelated ordered pairs as a constraint satisfaction network. A constraint satisfaction network consists of interconnected nodes. The nodes in the constraint satisfaction network are ordered pairs generated by the local applications of the principles of proportional analogy, mereological analogy, and extension to paradigmatic contrast sets. Connections in the constraint satisfaction network represent constraints between nodes. Consistent ordered pairs are linked by excitatory connections; inconsistent ordered pairs are linked by inhibitory connnections. Every node has a parameter called its activation. The activation of a node indicates the degree to which it satisfies the constraints in the network as a whole. The network of interconnected ordered pairs is run as a constraint satisfaction network using the formulae provided by McClelland \& Rumelhart $(1981,1989)$. As the network runs, the activations of nodes fluctuate but eventually stablize. Once the activations have stabilized, the ordered pairs that best satisfy the constraints in the network, and hence that best preserve the global relational 
structure of the source, are those with the highest activations. A map from the field of childbirth from Table 1 to the field of philosophy from Table 1 is shown in Table 2.

$\underline{\mathrm{f}_{\mathrm{M}}}:$ Source $\rightarrow$ Target
mother $\rightarrow$ student
womb $\rightarrow$ mind
baby $\rightarrow$ idea
egg $\rightarrow$ idea
midwife $\rightarrow$ teacher
liveborn $\rightarrow$ true
stillborn $\rightarrow$ false
S5 $\rightarrow$ T2
S6 $\rightarrow$ T3
S11 $\rightarrow$ T7
S15 $\rightarrow$ T10
S17 $\rightarrow$ T13
S18 $\rightarrow$ T14

Table 2. Analogical map $\mathrm{f}_{\mathrm{M}}$ for the fields in Table 1 .

\section{Generating Metaphors}

SFTM holds that metaphor is an utterance (written or spoken) in which some of the words (or phrases) come from a target field and others from an analogous but distinct source field. In such an utterance, words from the target are used literally, while words from the source are used metaphorically. Usage is indicated by subscripted "LIT" for literal and "MET" for metaphorical. For instance, in the sentence "[Socrates $]_{\text {LIT }}[\text { is }]_{\text {MET }}$

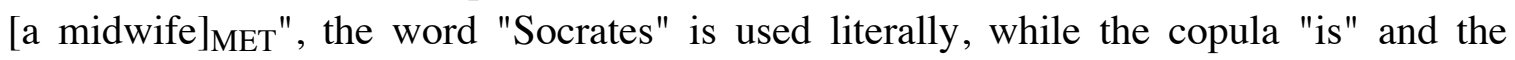
noun-phrase "a midwife" are used metaphorically.

Following Brook-Rose (1970) and Tirrell (1991), SFTM develops a grammar of metaphors. Traditional theories of metaphor have unfortunately focused almost exclusively on noun-identification metaphors of the form "An A is a B". In contrast with such theories, SFTM outlines almost a dozen different basic grammatical forms of metaphor. We believe that the ability to explain all the many forms of metaphor is essential; a theory that accounts only for noun-identification metaphors is no more a theory of metaphor than a theory that deals only with raccoons is a theory of animals. NETMET is able to generate metaphors of all the grammatical forms discussed by SFTM. Part of the significance of NETMET for the humanities is its ability to generate metaphors of high literary quality, not just metaphors like "An A is a B". A few of the grammatical forms supported by SFTM are shown in Table 3.

$\left[\mathrm{NOUN}_{1}\right]_{\mathrm{LIT}}[\mathrm{BE}]_{\mathrm{MET}}$ DET $[\mathrm{NOUN}]_{\mathrm{MET}}$

Socrates is a midwife.

$\left[\mathrm{NOUN}_{1}\right]_{\mathrm{LIT}}[\mathrm{BE}]_{\mathrm{MET}} \mathrm{DET}[\mathrm{ADJ} \text { NOUN } 2]_{\mathrm{MET}}$

The mind is an intellectual womb. 
$\left[\mathrm{NOUN}_{1}\right]_{\mathrm{LIT}}[\mathrm{BE}]_{\mathrm{MET}}$ DET $\left[\mathrm{NOUN}_{2}\right]_{\mathrm{MET}}[\mathrm{of}]_{\mathrm{LIT}}[\mathrm{NOUN}]_{\mathrm{LIT}}$ An idea is a child of the mind.

DET $[\mathrm{NOUN}]_{\mathrm{LIT}}[\mathrm{BE}]_{\mathrm{MET}}[\mathrm{ADJ}]_{\mathrm{MET}}$

Some ideas are stillborn.

$\left[\mathrm{NOUN}_{1}\right]_{\text {LIT }}[\mathrm{VERB}]_{\text {MET }}\left[\mathrm{NOUN}_{2}\right]_{\text {LIT }}$

Students give birth to ideas.

$\left[\mathrm{NOUN}_{1}\right]_{\text {LIT }}[\mathrm{VERB}]_{\mathrm{MET}}[\mathrm{NOUN}]_{\text {MET }}[\mathrm{of}]_{\mathrm{LIT}}\left[\mathrm{NOUN}_{3}\right]_{\mathrm{LIT}}$

A student gives birth to a child of his mind.

Table 3. Some grammatical forms of metaphors.

Once the global analogical map has been created, NETMET generates metaphors using generation rules appropriate to each grammatical form. Rules are presented below for generating metaphors of three grammatical forms: (1) noun-identification metaphors; (2) noun-identification metaphor with genitives; (3) verb predication metaphors. In these rules, angle brackets indicate that the enclosed expression is to be replaced with some particular value. For instance, the expression $<$ NOUN1 $>$ is replaced with a particular noun, such as "teacher". To express our rules, we also need a way to refer to the various roles nouns play in sentences. If $F$ is a sentential proposition, then AgentOf(F) is the noun that plays the AGENT role in F; likewise, PatientOf(F) is the noun that plays the PATIENT role, and $\operatorname{InstrOf}(\mathrm{F})$ is the noun that plays the INSTRUMENT role.

(1) Noun-Identification Metaphors.

If $\left(\exists \mathrm{S}, \mathrm{T}, \mathrm{f}_{\mathrm{M}}\right)\left(\left(\mathrm{S}, \mathrm{T}, \mathrm{f}_{\mathrm{M}}\right)\right.$ is an analogy \& $\left.\mathrm{NOUN}_{1} \in \mathrm{T} \& \mathrm{NOUN}_{2} \in \mathrm{S} \& \mathrm{NOUN}_{1}=\mathrm{f}_{\mathrm{M}}\left(\mathrm{NOUN}_{2}\right)\right)$

then $<\left[\mathrm{NOUN}_{1}\right]_{\mathrm{LIT}}[\mathrm{BE}]_{\mathrm{MET}}\left[\mathrm{DET} \mathrm{NOUN}_{2}\right]_{\mathrm{MET}}>$.

If $(\exists S, T, F, B)((S, T, F, B)$ is an analogy \& student $\in \mathrm{T} \&$ mother $\in \mathrm{S} \&$ student $=\mathrm{f}_{\mathrm{M}}($ mother $\left.)\right)$

then "[student $]_{\mathrm{LIT}}[\text { is }]_{\mathrm{MET}}[\text { a mother }]_{\mathrm{MET}}$ ".

(2) Noun-Identification Metaphors with Genitives.

If $\left(\exists \mathrm{S}, \mathrm{T}, \mathrm{f}_{\mathrm{M}}\right)\left(\left(\mathrm{S}, \mathrm{T}, \mathrm{f}_{\mathrm{M}}\right)\right.$ is an analogy \& $\mathrm{NOUN}_{1} \in \mathrm{T} \& \mathrm{NOUN}_{2} \in \mathrm{S} \& \mathrm{NOUN}_{1}=\mathrm{f}_{\mathrm{M}}\left(\mathrm{NOUN}_{2}\right) \&$

$\left(\exists \mathrm{NOUN}_{4}\right)\left(\left[\mathrm{of}\left(\mathrm{NOUN}_{2}, \mathrm{NOUN}_{4}\right)\right]_{\mathrm{LIT}} \in \mathrm{S} \&\right.$

$\left.\left.\mathrm{NOUN}_{3}=\mathrm{f}_{\mathrm{M}}\left(\mathrm{NOUN}_{4}\right)\right)\right)$

then $<\left[\mathrm{NOUN}_{1}\right]_{\text {LIT }}[\mathrm{BE}]_{\mathrm{MET}}$ DET $\left[\mathrm{NOUN}_{2}\right]_{\mathrm{MET}}$ of $\left[\mathrm{NOUN}_{3}\right]_{\text {LIT }}>$. 
If $\left(\exists S, T, f_{M}\right)\left(\left(S, T, f_{M}\right)\right.$ is an analogy \&

mind $\in \mathrm{T} \&$ womb $\in \mathrm{S} \&$ mind $=\mathrm{f}_{\mathrm{M}}($ womb $) \&$

(ヨbaby)( [of(womb, baby) $]_{\text {LIT }} \in \mathrm{S} \&$

idea $=f_{M}($ baby $\left.\left.)\right)\right)$

then $<[\text { The mind }]_{\text {LIT }}[\text { is }]_{\text {MET }}$ a $[\text { womb }]_{\text {MET }}$ of [ideas $]_{\text {LIT }}>$.

(3) Verb-Predication Metaphors.

If $\left(\exists S, T, f_{M}\right)\left(\left(S, T, f_{M}\right)\right.$ is an analogy \&

$\left(\exists \mathrm{P}_{\mathrm{S}}\right)\left(\mathrm{P}_{\mathrm{S}}\right.$ is a sentential proposition in $\mathrm{S} \&$

$\left(\sim\left(\exists \mathrm{P}_{\mathrm{T}}\right)\left(\mathrm{P}_{\mathrm{T}}=\mathrm{f}_{\mathrm{M}}\left(\mathrm{P}_{\mathrm{S}}\right)\right) \&\right.$

$\operatorname{NOUN}_{1}=\mathrm{f}_{\mathrm{M}}\left(\operatorname{AgentOf}\left(\mathrm{P}_{\mathrm{S}}\right)\right) \& \operatorname{VERB}=\operatorname{VerbOf}\left(\mathrm{P}_{\mathrm{S}}\right) \&$

$\left.\operatorname{NOUN}_{2}=\mathrm{f}_{\mathrm{M}}\left(\operatorname{PatientOf}\left(\mathrm{P}_{\mathrm{S}}\right)\right) \& \mathrm{NOUN}_{3}=\mathrm{f}_{\mathrm{M}}\left(\operatorname{InstrOf}\left(\mathrm{P}_{\mathrm{S}}\right)\right)\right)$

then $<[\text { NOUN1 }]_{\text {LIT }}[\mathrm{VERB}]_{\text {MET }}\left[\mathrm{NOUN}_{2}\right]_{\text {LIT }}$ with $\left[\mathrm{NOUN}_{3}\right]_{\text {LITT }}>$.

If $\left(\exists S, T, f_{M}\right)\left(\left(S, T, f_{M}\right)\right.$ is an analogy \&

(S14 is a sentential proposition in $\mathrm{S} \&$

$\left(\sim\left(\exists \mathrm{P}_{\mathrm{T}}\right)\left(\mathrm{P}_{\mathrm{T}}=\mathrm{f}_{\mathrm{M}}(\mathrm{S} 14)\right) \&\right.$

student $=$ AgentOf $\left(\mathrm{f}_{\mathrm{M}}(\mathrm{S} 14)\right) \&$ gives-birth $=\operatorname{VerbOf}(\mathrm{S} 14)$

$\&$ idea $=$ PatientOf $\left.\left.\left.\left(\mathrm{f}_{\mathrm{M}}(\mathrm{S} 14)\right)\right)\right)\right)$

then "[A student $]_{\text {LIT }}$ [gives birth $]_{\text {MET }}$ [to an idea $]_{\text {LIT" }}$.

\section{Analogical Transference}

Analogies are often used as speculative tools to generate new hypotheses about a target field. Such analogies have often provoked much debate in the humanities. For example, the analogy between the body and a watch (LaMettrie, 1912; Hobbes, 1962) and the pair of analogies linking the brain with the computer and the mind with the computer program (cf. MacCormac, 1985, ch. 1) both provoked much debate in the humanities. ${ }^{5}$ These analogies provoked debate primarily because they led to the generation of new theories of their targets, namely, the body and the brain (or mind). These new theories consisted of new target hypotheses.

New hypotheses in the target field are generated by a process called analogical transference. Analogical transference uses the analogical mapping function to move propositions from the source to the target. Analogical transference examines every proposition $\mathrm{P}$ in the source. If there is no analogous proposition for $\mathrm{P}$ in the target, then analogical transference (1) makes a copy of $P,(2)$ replaces every noun or adjective in the copy of $\mathrm{P}$ with its analogue; and (3) adds the copy of $\mathrm{P}$ to the target. In NETMET, sentential propositions, properties, features, and rules are transferred. Analogical 
transference produces a new target field; it results in the metaphorical redescription of the target field (Hesse, 1966). An example of analogical transference is shown in Table 5. Analogically transferred propositions are in boldface; words (or phrases) used metaphorically are enclosed in square brackets.
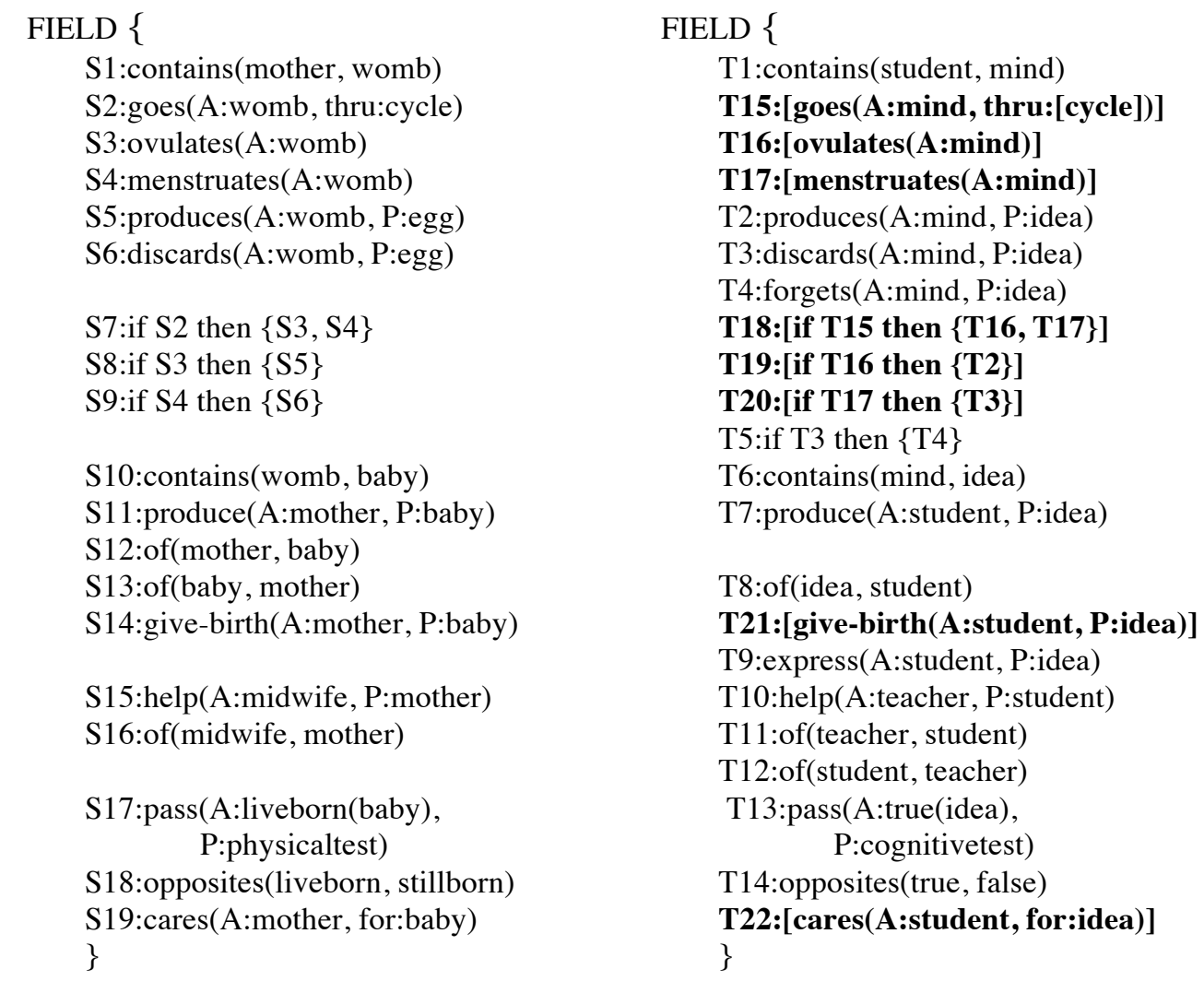

Table 4. Fields after analogical transference.

\section{Interpretation of Metaphors}

Metaphors, once created, require interpretation. Though the use of analogies may seem more relevant to the sciences, certainly the interpretation of metaphors is of primary concern to literary and artistic theory. According to Black $(1962,1979)$, metaphors are interpreted by generating implication complexes. Black's notion of an interpreting a metaphor by generating its implication complex has been refined and elaborated by Tourangeau (1982). In order to discuss the interpretation of metaphors, we need to discuss implication complexes. An implication complex consists of all the logical consequences of a proposition. Implication complexes are generated by the repeated application of rules. For instance, if it rains, then the ground gets wet; if the ground gets wet, then the car will slide; etc. The process of generating an implication complex is known as forward-chaining, because it generates a chain of inferences by moving forwards from the antecedent of a rule to its consequents (Lucas \& van der Gaag, 1991, ch 3). An implication complex has the form of a tree. Those propositions that have no consequences are the leaves of an implication complex. For example, the implication 
complex of "S2:goes(A:womb, thru:cycle)" is shown in Figure 1. The leaves are S5 and S6.

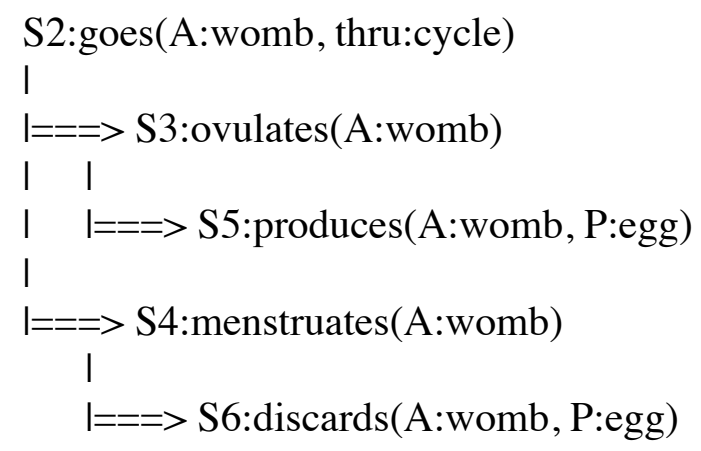

Figure 1. An implication complex.

Given a metaphorical proposition, in particular, given a metaphorical proposition produced by analogical transference, NETMET interprets the proposition by generating its implication complex. For example, the implication complex of "T15:[goes(A:mind, thru:[cycle])]" is shown in Figure 2. Notice that generation of the implication complex of a metaphor involves the use of analogically transferred rules.

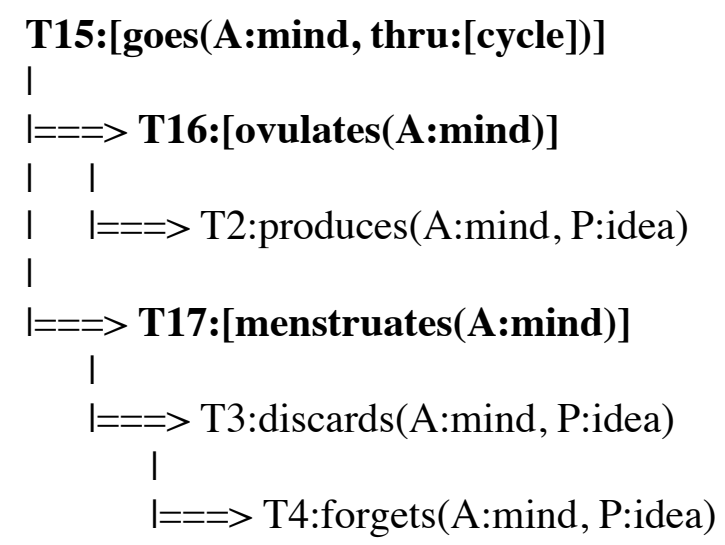

Figure 2. An implication complex for a metaphor.

The leaves of an implication complex are of particular interest. The conjunction of the literal leaves of the implication complex constitutes a partial literal interpretation or partial literal paraphrase of the metaphorical predication. A partial literal interpretation may be reduced to a complete literal interpretation simply by ignoring the non-literal leaves of the implication complex; this is what occurs when metaphors are literalized by repeated conventional use. Metaphors with complete literal interpretations are thus essentially dead metaphors. 


\section{Conclusion}

Based on a rich philosophical theory of the semantics of metaphor, NETMET is able to generate rich metaphors and to interpret metaphorical propositions. While NETMET provides computational confirmation for SFTM, NETMET also does more than that. NETMET shows that philosophical theories that deny semantics to metaphors are wrong. Metaphors are at least as rule-governed as literal language. As SFTM develops into a progressively more robust theory of metaphors, NETMET serves as a laboratory instrument for testing the expanding claims of SFTM. Already NETMET has both verified and falsified theoretical claims of SFTM, thus revealing its utility as a philosophical and linguistic research tool.

The success of NETMET as a model for generating and interpreting metaphors shows that at least one figure of speech has a computable semantics. While philosophy of language has so far focused on the kinds of literal discourse found in logic, mathematics, and a logically idealized version of science, such sanitized types of discourse are not common in nor appropriate to the humanities. It is hoped that the success of NETMET will bring the philosophy of language closer to the kinds of discourse used in literature, poetics, rhetoric, comparative studies, and other branches of the humanities. 


\section{Notes}

${ }^{1}$ NETMET is written in C and runs on IBM PCs with 286 processors or better. The source code for NETMET totals approximately 20,000 lines. NETMET can be downloaded from the APA Bulletin Board, reachable through the gopher server at apa.oxy.edu; alternatively, it can be obtained from the author.

${ }^{2}$ Although NETMET can pick a cue on its own, it is usually more interesting for the user to select a cue.

${ }^{3}$ Usually this is done by the user, but NETMET can make such selections on its own.

${ }^{4}$ Again, NETMET can do this by itself, but it's usually more interesting for the user to do it. NETMET provides the option unless there is only one source.

${ }^{5}$ Such analogies have been both praised as seeds of scientific progress, and condemned as pseudo science (cf. Arendt, 1971, Vol. 1, p. 113). It is hoped that a rigorous theory, like SFTM and NETMET, can shed light on the significance and truth-value of such analogies. Indeed, the research that led to NETMET was provoked by concern with the excesses of the analogies drawn between the computer (or program) and the brain (or mind). 


\section{Bibliography}

Arendt, H. (1971) The Life of the Mind. Vol. 1, Thinking. Part II, Chs. 12 \& 13. New York: Harcourt Brace Jovanovich.

Aristotle. (1987) Poetics. R. Janko (Trans.) Indianapolis: Hackett.

Black, M. (1962) Metaphor. In M. Black, Models and Metaphors. Ithaca, NY: Cornell University Press.

Black, M. (1979) More about metaphor. In Ortony (1979), pp. 19-43.

Brooke-Rose, C. (1970) A Grammar of Metaphor. London: Seeker and Warburg.

Carbonell, J. G. \& Minton, S. (1985) Metaphor and commonsense reasoning. In Hobbs \& Moore, Formal Theories of the Commonsense World. Norwood, NJ: Ablex Publishing.

Collins, A. M., \& Loftus, E. F. (1975) A spreading-activation theory of semantic processing. Psychological Review, 82, 407-428.

Cragg, B. G. \& Temperley, N. V. (1954) The organization of neurones: A cooperative analogy. EEG Clinical Neurophysiology 6 (85).

Cruse, D. A. (1986) Lexical Semantics. New York: Cambridge Univ. Press.

Davidson, D. (1978) What metaphors mean. In A. P. Martinich (Ed.), The Philosophy of Language. New York: Oxford University Press.

de la Mettrie, J. O. (1912) Man a machine. G. C. Bussey \& M. W. Calkins (trans.). LaSalle, IL: Open Court. Original work published 1748.

Falkenhainer, B., Forbus, K. D, \& Gentner, D. (1989) The structure-mapping engine: Algorithm and examples. Artificial Intelligence, 41, 1-63.

Gentner, D. (1982) Are scientific analogies metaphors? In D. S. Miall (Ed.), Metaphor: Problems and Perspectives. New York: The Humanities Press.

Gentner, D. (1983) Structure-mapping: A theoretical framework for analogy. Cognitive Science, 7, 155-170.

Gentner, D., Falkenhainer, and Skorstad, J. (1988) Viewing metaphor as analogy. In Helman (1988), pp. 171-178.

Goodman, N. (1976) Languages of Art. Indianapolis: Hackett. 
Hall, R. P. (1989) Computational approaches to analogical reasoning: A comparative analysis. Aritificial Intelligence, 39, 39-120.

Hesse, M. (1966) Models and Analogies in Science. Notre Dame, IN: Notre Dame University Press.

Hobbes, T. (1962). Leviathan: Or the matter, forme, and power of a commonwealth ecclesiastical and civil. M. Oakeshott (Ed.). New York: Collier MacMillan. Original work published 1651.

Holyoak, K., \& Thagard P. (1989) Analogical mapping by constraint satisfaction. Cognitive Science, 13, 295-355.

Holyoak K., \& Thagard, P. (1990) A constraint-satisfaction approach to analogue retrieval and mapping. In K. J. Gilhooly, M. T. G. Keane, R. H. Logie \& G. Erdos (Eds.), Lines of Thinking (Vol. 1). New York: John Wiley \& Sons.

Indurkhya, B. (1987) Approximate semantic transference: A Computational theory of metaphors and analogies. Cognitive Science, 11, 445-480.

Kintsch, W. (1972) Notes on the structure of semantic memory. In Tulving \& Donaldson (1972), pp. 247-308.

Kittay, E. F. (1987) Metaphor: Its Cognitive Force and Linguistic Structure Oxford: Oxford University Press.

Lakoff, G. \& Johnson, M. (1980) Metaphors We Live By. Chicago: University of Chicago Press.

Lucas, P. \& van der Gaag, L. (1991) Principles of Expert Systems. New York: Addison-Wesley.

Lyons, J. (1977) Semantics. Cambridge: Cambridge University Press.

MacCormac, E. R. (1985). A Cognitive Theory of Metaphor Cambridge, MA: The MIT Press.

McClelland, J. L. \& Rumelhart, D. E. (1981) An interactive activation model of context effects in letter perception: Part 1. An account of basic findings. Psychological Review, 88, 375-407.

McClelland, J. L. \& Rumelhart, D. E. (1989) Explorations in parallel distributed processing: A handbook of models, programs, and exercises. Cambridge, MA: MIT Press / Bradford Books. 
Miall, D. S. (1982) Metaphor: Problems and Perspectives. Atlantic Highlands, NJ: Humanities Press.

Miller, G. A. (1979) Images and models, similes and metaphors. In A. Ortony (1979).

Miller, G. A. (Ed.) (1990) WordNet: An on-line lexical database. International Journal of Lexicography, Vol. 3, No. 4. (Entire volume.)

Norman, D. A. \& Rumelhart, D. E. (1975) Explorations in Cognition. San Francisco: W. H. Freeman.

Ortony, A. (Ed.) (1979) Metaphor and Thought. Cambridge: Cambridge University Press.

Plato (1984) Theatetus. S. Bernardete (Trans.). Chicago: University of Chicago Press.

Rumelhart, D. E., McClelland, J., L., et al (1986). Parallel Distributed Processing (Vol. 1). Cambridge MA: MIT Press.

Schank, R. \& Abelson, R. (1977) Scripts, Plans, Goals and Understanding: An Inquiry into Human Knowledge Structures. Hillsdale, NJ: Lawrence Erlbaum.

Steinhart, E. \& Kittay, E. (Forthcoming) Generating metaphors from networks: A formal interpretation of the semantic field theory of metaphor. In J. Hintikka (Ed.), Approaches to Metaphor. Kluwer Academic.

Tirrell, L. (1991) Reductive and nonreductive simile theories of metaphor. Journal of Philosophy, Vol. 88, No. 7, 337-358.

Tourangeau, R. (1982) Metaphor and cognitive structure. In D. S. Miall (1982).

Tulving, E. \& Donaldson, W. (Eds.). (1972) Organization of Memory. New York: Academic Press. 